\title{
Peran Pendidikan Non Formal Dalam Pemberdayaan Masyarakat Berbasis Potensi Wisata Alam Bukit Teletabis
}

\author{
Ismaniar $^{1}$, Ilsadul Ilbad ${ }^{2}$ \\ Pendidikan Luar Sekolah, Fakultas Ilmu Pendidikan, Universitas Negeri Padang \\ ismaniar.js.pls@fip.un.ac.id, ilsadulilbat03@gmail.com
}

Received: 27 Juni 2021; Revised: 27 Juni 2021; Accepted: 29 Juni 2021

\begin{abstract}
This research is motivated by the development of the Teletabis Hill Nature tourism location in Pasaman Regency. However, community involvement and participation in tourism site development activities is less visible. The research aims to find out; What is the form of community involvement in the development of Teletabiss Hill natural tourism, and why is public participation less visible in the development of Teletabiss Hill natural tourism sites. This research is a qualitative descriptive study. The data was collected by using observation and interview techniques, while the respondents were using purposive random sampling technique. Based on the results of the study it was concluded that; In general, community involvement in Bukit Teletabis tourism development activities is only on the use of the location for personal interests, namely as a place to trade. The community considers development efforts to be the duty of the government and existing youth organizations. Meanwhile, the lack of community participation in Bukit Teletabis tourism development activities is due to a lack of public knowledge about the forms of responsibility they can take. This was revealed because the community was not involved in the discussion of tourism site development activities. It is recommended to increase the active role of the community, empowerment activities are carried out by the authorities. Empowerment activities should be carried out with non-formal education so that it is more flexible with the conditions and needs of a very heterogeneous community.
\end{abstract}

\section{Keywords: Role, PNF, Empowerment. Community, Nature Tourism}

\begin{abstract}
ABSTRAK
Penelitian ini dilatar belakangi berkembangnya lokasi wisata Alam Bukit Teletabis di Kabupaten Pasaman. Namun keterlibatan dan partisipasi masyarakat dalam kegiatan pengembangan lokasi wisata kurang terlihat. Penelitian bertujuan mengetahui; Bagaimana bentuk keterlibatan masyarakat dalam pengembangan wisata alam Bukit Teletabis, dan mengapa partisipasi masyarakat kurang terlihat dalam pengembangan lokasi wisata alam Bukit Teletabiss. Penelitian ini merupakan penelitian deskriptif kualitatif. Pengumpulan data dilakukan dengan Teknik observasi dan wawancara, sedang pengambilan responden dengan Teknik purporsive randam sampling. Berdasarkan hasil penelitian disimpulkan bahwa; secara umum keterlibatan masyarakat dalam kegiatan pengembangan wisata Bukit Teletabis hanya pada pemanfaatan lokasi bagi kepentingan pribadi yaitu sebagai tempat berdagang. Masyarakat menganggap upaya pengembangan merupakan tugas pemerintah dan organisasi pemuda yang ada. Sementara kurangnya partisipasi masyarakat dalam kegiatan pengembangan wisata Bukit Teletabis karena kurangnya pengetahuan masyarakat tentang bentuk tanggungjawab yang dapat mereka lakukan. Hal ini terungkap dikarenakan masyarakat tidak dilibatkan dalam pembahasan kegiatan pengembangan lokasi wisata. Disarankan untuk meningkatkan peran aktif masyarakat dilakukan kegiatan pemberdayaan oleh pihak yang berwenang. Kegiatan pemberdayaan sebaiknya dengan Pendidikan non formal sehingga lebih fleksibel dengan kondisi dan kebutuhan masyarakat yang sangat heterogen.
\end{abstract}

Kata kunci: Peran, PNF, Pemberdayaan. Masyarakat, Wisata Alam.

(C)2021 Ismaniar, Ilsadul Ilbad Under the license CC BY-SA 4.0 


\section{PENDAHULUAN}

Kehidupan masyarakat yang sejahtera dan damai merupakan cita-cita utama dari setiap upaya pembangunan yang dilakukan oleh berbagai negara. Kesejahteraan masyarakat salah satunya dapat dilihat dari kemandirian yang mereka tunjukkan dalam memenuhi tuntutan kebutuhan diri dan keluarganya sesuai standar ideal yang dimiliki oleh negara tersebut. Semakin tingginya tingkat persaingan dalam memperoleh peluang dalam dunia kerja, membuat banyak warga masyarakat yang tidak dapat memberikan kehidupan yang layak bagi diri dan keluarganya. Fenomena tersebut juga terjadi di negara kita Indonesia.

Menyikapi fenomena tersebut, maka masyarakat perlu kreatif dalam melihat berbagai potensi yang ada di lingkungan sekitarnya yang dapat digali dan dikembangkan. Sehingga menjadi sumber pendapatan bernilai ekonomi untuk meningkatkan kesejahteraan keluarga. Berdasarkan survey dan penelusuran penulis ke daerah Pasaman yang ada di Propinsi Sumatera Barat, penulis melihat banyak sekali potensi wisata yang ada dan dapat menjadi sumber untuk peningkatan kehidupan ekonomi masyarakat. Kondisi alam di Sumatera Barat khususnya di Kabupaten pasaman sangat komplek, menawarkan berbagai pesona dan keindahan alam dan budaya masyarakat yang eksotis. Diantaranya terdapat daerah dataran tinggi yang dilengkapi dengan wilayah pegunungan dan perbukitan yang masih terjaga kelestariannya, wilayah dataran rendah dengan kondisi pantai yang masih asri, terdapatnya beberapa lokasi cagar alam serta ditunjang dengan tradisi dan budaya yang dimiliki oleh masyarakat. Hal ini di dukung dengan data yang menjelaskan bahwa Tercatat 27 obyek pariwisata yang ada, terdiri dari 19 lokasi wisata alam (panorama, cagar alam, hutan lindung dan sumber air panas) dan 8 wisata sejarah dari obyek wisata tersebut, salah satunya terdapat obyek wisata Bukit Telatabis di Nagari Lubuak Layang (Pasaman, 2019)

Berdasarkan hasil pengamatan dan wawancara yang peneliti lakukan di daerah wisata Bukit Teletabis Kabupaten Pasaman, sebenarnya sudah ada usaha yang dilakukan dalam rangka mengembangkan wilayah wisata Bukit Teletabis ini, namun usaha yang terjadi masih berpusat pada sekelompok orang yang tergabung pada organisasi pemuda tertentu. Menurut Setijawan (dalam, Ilbat \& Ismaniar, 
2018) bahwa pariwisata berbasis masyarakat merupakan pendekatan pemberdayaanyang melibatkan masyarakat sebagai pelaku penting dalam konteks paradigma baru pembangunanyakni pembangunan yang berkelanjutan (sustainable development paradigma). Pariwisata berbasismasyarakat merupakan peluang untuk menggerakkan segenap potensi dan dinamika masyarakat, guna mengimbangi peran pelaku usaha pariwisata skala besar.Tantangan mewujudkan (sustainable tourism model) model kepariwisataan yang berkelanjutan melalui pelibatan masyarakat memerlukan usaha pemberdayaan kepada masyarakat secara serius (Setijawan, 2018). Sementara dukungan dari masyarakat belum terlihat dengan jelas. Masyarakat masih menunjukkan sikap menerima manfaat tanpa ada usaha yang lebih untuk meningkatkan pesona tempat wisata yang ada. Berdasarkan latar belakang di atas maka penulis melihat bahwa diperlukan peran pendidikan non formal dalam pemberdayaan masyakat berbasis Potensi Wisata Alam Bukit Teletabis di Kabupaten Pasaman Propinsi Sumatera Barat.

\section{METODE}

Penelitian ini menggunakan pendekatan deskriptif kualitatif dengan pendekatan survey. Bogdan dan Taylor (dalam Suwandi, 2008), menjelaskan pendekatan ini memberikan gambaran mengenai tulisan, perilaku serta kata-kata agar dapat diamati oleh kelompok, individu, masyarakat atau organisasi di lingkungan tertentu. Pengumpulan data dilakukan dengan pengamatan langsung dan dilengkapi dengan wawancara dengan beberapa responden dianggap memiliki informasi dan pemahaman tentang masyarakat dan kondisi wisata alam Bukit Teletabis Kabupaten pasaman. Responden di ambil melalui pendekatan purporsive random sampling.

\section{HASIL DAN PEMBAHASAN}

\section{Hasil}

Sesuai dengan pertanyaan penelitian yang ingin peneliti jawab melalui penelitian ini yaitu bagaimana bentuk keterlibatan masyarakat dalam pengembangan wisata alam Bukit Teletabis, serta Mengapa partisipasi masyarakat 
kurang terlihat dalam upaya pengembangan lokasi wisata alam Bukit Teletabis di Kapupaten Pasaman.

Berdasarkan data hasil penelitian yang peneliti dapatkan melalui metode survey dan wawancara langsung dengan beberapa orang responden yang terpilih maka di dapatkan data bahwa; bentuk keterlibatan masyarakat dalam kegiatan pengembangan lokasi wisata Bukit Teletabis lebih kepada pengambilan manfaat saja. Hal ini ditunjukkan dengan banyaknya warga masyarakat setempat yang berjualan di lokasi menuju Bukit Teletabis. Mereka membawa dagangannya ke lokasi terutama pada waktu-waktu jumlah pengunjung ramai seperti setiap hari minggu dan hari-hari libur. Di samping itu juga ada masyarakat yang sengaja membuka lapak atau warung di lokasi sekitar jalan menuju tempat wisata. Namun partisipasi masyarakat kurang terlihat pada kegiatan-kegiatan yang bersifat layanan fasilitas umum, seperti menjaga kebersihan fasilitas umum, kehadiran waktu kerja bakti untuk perbaikan jalan dan fasilitas. Sebagian besar mereka menganggap hal tersebut bukan menjadi tanggung jawabnya karena ada organisasi kelompok pemuda yang sudah memperhatikan hal tersebut. Berikut gambaran partisipasi masyarakat dalam kegiatan Pengembangan lokasi wisata Bukit Teletabis, berdasarkan informasi informan penelitian.

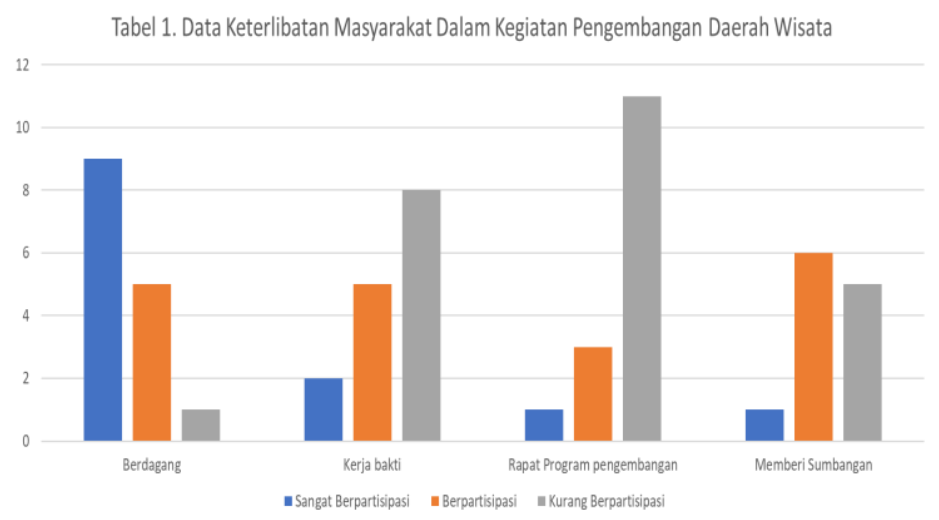

Selanjutnya terkait pertanyaan penelitian tentang mengapa partisipasi masyarakat kurang terlihat dalam pengembangan lokasi wisata Bukit Teletabis, data hasil penelitian yang diperoleh melalui survey dan wawancara menunjukkan bahwa sebahagian masyarakat kurang memahami tentang bentuk-bentuk tanggungjawab masyarakat dalam kegiatan pengembangan lokasi wisata. 
Sebahagian besar mereka menyatakan bahwa yang bertanggung jawab untuk itu adalah pemerintah dan organisasi pemuda yang ada. Lebih jauh dari hasil wawancara yang dilakukan juga terungkap bahwa sebagian masyarakat merasa sering tidak mendapat informasi dan kurang dilibatkan oleh organisasi pemuda yang sudah ditunjuk dalam pertemuan-pertemuan yang membicarakan hal-hal yang akan dilakukan untuk pengembangan lokasi wisata. Ada juga yang berpendapat bahwa dengan ikut menyumbang atau memberi iuran pada waktuwaktu tertentu mereka tidak lagi memiliki kewajiban yang lainnya.

\section{Pembahasan}

Berdasarkan hasil penelitian yang diperoleh di lapangan maka dapat diketahui bahwa bentuk keterlibatan dari warga masyarakat dalam pengembangan lokasi wisata Bukit Teletabis menunjukkan bahwa masyarakat berperan sebagai pengambil manfaat dari adanya lokasi wisata yang ada di daerah tersebut. Selanjutnya terkait mengapa partisipasi masyarakat kurang terlihat diperoleh data bahwa masyarakat kurang memahami bentuk-bentuk tanggungjawab yang dapat mereka berikan. Sebagian besar responden menjawab bahwa untuk tanggungjawab pengembangan dan berpikir tentang keberlangsungan lokasi wisata adalah apparat setempat dan organisasi pemuda setempat.

Berdasarkan hasil penelitian yang di peroleh maka ini menunjukkan bahwa ketidaktahuan atau ketidak pahaman masyarakat membuat mereka tidak banyak berbuat dan terkesan kurang peduli dengan upaya pengembangan lokasi wisata Bukit Teletabis. Menyikapi hal tersebut maka diperlukan upaya pemberdayaan untuk meningkatkan pengetahuan dan kesadaran warga masyarakat. Pengetahuan dan keterampilan yang diterima oleh Masyarakat melalui kegiatan pemberdayaan yang dilakukan akan membuat masyarakat berperan aktif dalam Setiap kegiatan yang menunjang peningkatan kesejahteraannya. Carver dan Clatter Back dalam (Putra, Wegi Trio, Ismaniar, 2020), menjelaskan bahwa pemberdayaan merupakan upaya untuk memberdayakan individu untuk mengambil tanggung jawab individu dalam perbaikan diri mereka dan untuk berkontribusi pada tujuan organisasi. Lebih jauh tentang mengapa menjadi penting sekali upaya pemberdayaan 
dilakukan dikarenakan makna yang terkadung dalam suatu proses pemberdayaan itu mencakup beberapa komponen yaitu adanya upaya pengembangan potensi, kegiatan penguatan potenti yang ada serta keinginan untuk mewujudkan suatu kondisi yang mandiri. Lebih jelasnya hal ini juga sejalan dengan yang dikemukakan oleh Wahyuni bahwa proses pemberdayaan itu pada dasarkan mencakup kegiatan pengembangan, memperkuat potensi dan tercapainya kemandirian (Wahyuni, 2018). Kegiatan pemberdayaan yang dilakukan diharapkan mengantarkan masyarakat yang belum memiliki daya/kekuatan berubah menjadi masyarakat yang menunjukkan kemandirian.

Selanjutnya adapun terkait teknis pelaksanaan proses pemberdayaan Suharto memiliki pandangan bahwa ada $5 \mathrm{P}$ yang harus dilakukan dalam proses pemberdayaan masyarakat (Suharto, 2014) terdiri dari;1) Kegiatan Pemungkinan, yaitu menciptakan suasana agar potensi yang dimiliki masyarakat dapat berkembang secara lebih baik, dengan cara mempertimbangkan masalah yang akan muncul 2) Kegiatan Penguatan, yaitu upaya membangun pengetahuan dan kapasitas untuk memenuhi kebutuhan mereka. 3) Kegiatan Perlindungan, yaitu adanya upaya untuk melindungi masyarakat yang lemah agar tidak tertindas oleh yang kuat atau menghindari persaingan yang tidak seimbang. 4) Kegiatan Penyokongan, yaitu ditandai dengan adanya dukungan dan nasihat agar warga masyarakat mampu memenuhi peran dan tugas dalam kehidupannya. 5) Kegiatan Pemeliharaan, yaitu adanya upaya memelihara keadaan yang menguntungkan antara berbagai kelompok dalam masyarakat.

Terkait dengan kondisi atau fenomena yang ditemukan dilokasi penelitian maka upaya pemberdayaan hendaknya menggunakan pendekatan Pendidikan non formal. Hal ini dikarenakan sasaran layanan pendidikan merupakan masyarakat secara umum adalah orang dewasa dan dengan latar belakang yang sangat heterogen, sehingga tidak mungkin dihadapi dengan Pendidikan formal. Menurut Solfema ada beberapa karakteristik orang dewasa yang perlu diperhatikan ketika kita membelajarkan orang dewasa, tidak dapat disamakan begitu saja dengan membelajarkan anak2 (Yuse et al., 2018). Salah satu keunggulan Pendidikan non formal adalah daya adaptif dalam penyelenggaraan proses pendidikan itu sendiri. 
Pelaksanaan Pendidikan non formal bisa diberikan kepada semua kelompok masyarakat, proses pelaksanaan pendidikan dapat disepakati baik terkait tempat, waktu maupun materi.

Lebih lanjut, ciri khas pelaksanaan kegiatan pembelajaran melalui Pendidikan non formal sangat memperhatikan dan mempertimbangkan minat/ perhatihan serta kebutuhan dari peserta belajar. Seorang pendidik non formal yang baik selalu mengupayakan agar minat belajar peserta selalu meningkat, setidaknya stabil. Misalnya dengan cara meningkatnya pemahaman peserta belajar tentang betapa bermanfaatnya pengetahuan yang diberikan untuk perkembangan kehidupan mereka ke depan. Terkait permasalahan yang ditemukan dalam penelitian ini tentunya menanamkan kepada masyarakat betapa besar manfaat yang bisa mereka terima, jika lokasi wisata tempat mereka berusaha sehari-hari dapat dikembangkan dengan baik. Pemahaman yang benar tentunya diharapkan menumbuhkan minat untuk mempelajari bentuk dan jenis partisipasi yang dapat mereka berikan. Terkait pentingnya minat dalam kegiatan belajar Slameto menjelaslan minat belajar memiliki pengaruh yang besar terhadap prestasi dan partisipasi belajar, karena jika bahan pelajaran yang dipelajari tidak sesuai dengan minat warga belajar, warga belajar tidak akan belajar dengan baik (Yulidar et al., 2018). Pendidikan nonformal proses pemberdayaan masyarakat dapat disesuaikan dengan kondisi dan kebutuhan masyarakat.

\section{SIMPULAN}

Berdasarkan hasil penelitian yang diperoleh maka dapat disimpulkan bahwa;

1. Bentuk keterlibatan masyarakat pada kegiatan di lokasi wisata Bukit teletabis lebih banyak terpusat pada kegiatan pemanfaatan lokasi wisata sebagai tempat berdagang atau berusaha.

2. Kurangnya keterlibatan masyarakat dalam kegiatan pengembangan lokasi wisata alam Bukit Teletabis disebabkan karena kekurangtahuan mereka tentang bentu-bentuk tanggung jawab yang bisa mereka berikan. Disamping itu 
masyarakat juga kurang mendapat informasi dan tidak terlibat langsung dalam kegiatan pembahasan atau diskusi tentang rencana pengembangan lokasi wisata

3. Upaya pemperdayaan perlu diberikan kepada warga masyarakat agar mereka bisa berperan aktif dan ikut mengembangkan lokasi wisata alam Bukit Teletabis, pemberdayaan juga akan mempengaruhi berbagai potensi yang di miliki warga sehingga nantinya mendukung mereka untuk mandiri.

4. Proses pemberdayaan masyarakat membutuhkan peran Pendidikan non formal karena memliki karakteristik pembelajaran yang adaptif dengan kebutuhan dan kondisi masyarakat yang cukup heterogen.

\section{DAFTAR PUSTAKA}

Ilbat, I., \& Ismaniar, I. (2018). Gambaran Pemberdayaan Masyarakat oleh Komunitas Pemuda Pambangun Nagari. Spektrum: Jurnal Pendidikan Luar Sekolah (PLS), 1(3). https://doi.org/10.24036/spektrumpls.v1i3.100262 Pasaman, D. P. K. (2019). Destinasi wisata.

Putra, Wegi Trio, Ismaniar, I. (2020). Pemberdayaan Masyarakat Melalui Pengelolaan Sampah Pendahuluan Proses pemberdayaan masyarakat dalam pendidikan nonformal sebenarnya merupakan upaya memberdayakan masyarakat untuk memperkuat seluruh eksistensinya . Menitikberatkan pada kegiatan yang seharu. Jambura, 1(2), 1-10.

Setijawan, A. (2018). Pembangunan Pariwisata Berkelanjutan dalam Perspektif Sosial Ekonomi. Jurnal Planoearth, 3(1), 7. https://doi.org/10.31764/jpe.v3i1.213

Suharto. (2014). Membangun Masyarakat Memberdayakan Masyarakat, KajianStrategis Pembangunan Kesejahteraan Sosial \& Pekerjaan Sosial. Refika Aditama.

Suwandi, \& B. (2008). Memahami Penelitian Kualitatif. Rineka Cipta.

Wahyuni, D. (2018). Strategi Pemberdayaan Masyarakat Dalam Pengembangan Desa Wisata Nglanggeran, Kabupaten Gunung Kidul. Aspirasi, 9(1), 83-100. http://jurnal.dpr.go.id/index.php/aspirasi/index

Yulidar, Y., Syuraini, S., \& Ismaniar, I. (2018). Gambaran Minat Warga Belajar Mengikuti Kegiatan Randai di Sanggar Seni Mustika Minang Duo Kota Pariaman. Spektrum: Jurnal Pendidikan Luar Sekolah (PLS), 1(2), 245. https://doi.org/10.24036/spektrumpls.v1i2.9489 
Yuse, A. P., Jamaris, J., \& Ismaniar, I. (2018). Penerapan Pembelajaran Orang Dewasa oleh Instruktur Pelatihan Keterampilan Menjahit di SPNF SKB Lima Puluh Kota. Spektrum: Jurnal Pendidikan Luar Sekolah (PLS), 1(1), 16. https://doi.org/10.24036/spektrumpls.v1i1.9199 